\title{
IMPLIED MONETARY POLICY EXTRACTED FROM INTEREST RATE SWAPS IN CHILE
}

TASAS DE POLITICA MONETARIA IMPLICITAS EXTRAIDAS DE LA CURVA SWAP EN PESOS CHILENOS

\section{RODRIGO CALCAGNI T.*}

Economics Department, United World College of the Adriatic

\begin{abstract}
This article describes a methodology that uses interest rate swaps in Chilean Pesos to extract monetary policy paths, as well as their probability, with nodes on future Central Bank meetings. It is concluded that implied policy paths contain term premiums that correlate with the policy cycle. Accordingly, implied paths have consistently overestimated the future path of future interest rates, pricing hikes more often than cuts and underestimating the likelihood of rates becoming more expansionary. Moreover, the level of implied rates has been governed by the front end of the curve, instead of expectations of the economic cycle. The result is that extracting implied rates from the swap curve is an ineffective tool for forecasting, and that the swap curve has not been able to anticipate changes in policy. These findings provide insights on the asymmetrical risk profile of future monetary policy and may contribute to the design of hedging strategies.
\end{abstract}

Keywords: Monetary policy, interest rate swaps, term premium, implied rates of monetary policy, swap cámara promedio.

JEL Classification: $G 1$.

* E-mail: rodrigocalcagni@gmail.com 


\section{Resumen}

Este artículo describe una metodología que utiliza swaps de tasa de interés en pesos chilenos para extraer sendas de tasas de política monetaria futuras, junto a sus probabilidades de ocurrencia, con nodos en eventuales reuniones del Banco Central. Se concluye que tales sendas implícitas de política contienen premios por plazo que están correlacionados con el ciclo de política. Así, los derivados de tasas han sobrestimado de manera consistente la senda de política monetaria futura, incorporando en sus precios aumentos de TPM más frecuentemente que recortes de tasa y han subestimado la probabilidad de recortes. Más aún, el nivel de tasas implícitas ha sido determinado por la parte corta de la curva en vez de por expectativas sobre el ciclo económico. El resultado es que extraer tasas implícitas de la curva swap es un método inefectivo para predecir tasas futuras y que estas no anticipan decisiones de política. Estos resultados ayudan a entender el perfil asimétrico del riesgo de movimientos futuros de política monetaria y pueden contribuir al diseño de estrategias de cobertura.

Palabras clave: Politica monetaria, swaps de tasa de interés, premios por riesgo, tasas de política monetaria implícitas, swaps cámara promedio, índice de cámara promedio, tasa nominal anualizada

Clasificación JEL: G1.

\section{INTRODUCTION}

This article examines a methodology to extract forward looking paths of monetary policy that are implied in, and can be extracted from, the swap curve in Chile. It also describes the dynamics of implied future interest rate paths and discusses their effectiveness in anticipating changes in monetary policy. The sample to obtain implied rates is comprised of daily closings for the swap curve (contracts in Chilean Pesos) between January 2011 and September 2017. Up to fifteen months forward implicit rate paths are put to test against actual monetary policy and their dynamics are compared to past and ex-post information (up until December 2018). It is concluded that swap contracts consistently price higher than average monetary policy rates, and that such differences directly correlate with policy cycles which can be interpreted as term premiums. This means that term premiums have been higher during periods of tightening and vice versa. Moreover, it is shown that the level of up to fifteen months ahead rates ${ }^{1}$ is governed by the front end of the curve and the current level of policy. These findings are contrary to

1 The rate that is implied for the monetary policy decision fifteen months in the future. 
what would be expected for a Central Bank that targets inflation and that normalizes monetary policy once inflation reaches its target in the projection horizon ${ }^{2}$.

In the sample period, the variance of the whole path of implied rates is tied to the variance of one month ahead rates. This means that both the level, and the volatility of implied rates are determined by the front end of the curve (both by its level and by its volatility). It follows that changes in implied future rates are strictly determined and can only be caused by unexpected changes in monetary policy or by the slope of the zero coupon swap curve ${ }^{3}$. It is also concluded that the swap curve is ineffective for pricing one meeting ahead changes in policy, and that it prices hikes more often than it does cuts, contrary to the actual history of monetary policy cycles. In fact, it is shown that the Central Bank has often acted in different ways than the market has been pricing, but that the market has been swift to adapt when surprised. Finally, it is shown that implied monetary policy rates as described in this article have not been able to anticipate future monetary policy and that pricing errors correlate with current monetary policy.

This article is organized in three parts. The first one provides a short review of the existing literature and the international experience regarding expectations of American monetary policy based on the widely used methodologies that rely on Federal Fund Rate Futures. It also looks into local articles regarding derivatives in Chile and on their proposed uses for extracting future monetary policy expectations. The second part provides a description of the methodology used, as well as a numerical example. With this in mind, the example provided fulfills a secondary aim of this article, which is to present its methodology in a simple way that can be replicated and understood by practitioners. In particular, the methodology described projects the underlying index for the netting of plain vanilla interest rate swaps (índice de cámara promedio) and extracts the implicit movements of monetary policy rates and their likelihoods. In this simple example, many of the conclusions of the article are shown in a simple manner. Finally, the third part uses historical data to put to test implicit monetary policy rates against the actual actions taken by the Central Bank and their dynamics are compared to past and ex-post information.

\section{LITERATURE REVIEW AND INTERNATIONAL EVIDENCE}

Most existing literature focuses on Federal Fund Rate Futures (FFRF) and their use for extracting expectations of FOMC meetings decisions. With an educational purpose, Keasler and Goff (2007) describe in a straightforward fashion a commonly used methodology to extract Fed Fund Rate decisions in upcoming FOMC meetings from interest rate futures. Such methodology is based on the assumptions that (i) FFR

2 The standard for the Central Bank of Chile.

3 Given the path of monetary policy that is extracted from the derivatives contracts, expected movements in the zero coupon swap curve are based on the time decay of the contract 
are always at the target and (ii), FFR can only jump by 25bp. Nosal (2001) states that as much as FFRF do provide a measure of expected rates in an efficient market, it is sensible for them to price higher rates given the nature of the hedge they provide. In fact, while FFRF can help manage risk from movements in interest rates, these are determined by other financial instruments. In this case, FFRF hedge pure discount bonds as they fix the selling price in the future (or rather, the return of the buy-andhold strategy). To compensate for risk, the expected price of the bond must be higher than that of the forward fixing the price, thus yielding a higher rate for the FFRF. In this way, a premium for compensating buyers for this risk is incorporated into the future rates. For a twelve year sample ending in 2001, they show that FFRF tend to overestimate actual future rates when rates are falling, and underestimate them when they are hiking, or that they fail to interpret the monetary policy cycle.

Similar conclusions are reached by Emmons and Yeager (2002), who determine that FFRF are better at predicting that rates will remain unchanged, and that they tend to predict hikes more often than cuts. Fontaine (2016) shows that volatility in the distribution of expected changes in FFRs depends on the cycle of policy, and that it is lower for tightening cycles. This means that market participants seem more assertive in pricing hikes than cuts. Both of these predictions are shown by the data presented in this article.

For the Chilean market, two papers closely examine the underlying methodologies for interest rate swap (IRS). Sotz and Alarcón (2007) describe the functioning of IRS in the local market and how forward rates may be used as proxies for monetary policy expectations. Varela (2007) approaches the methodology comprised in this article and focuses on the projection of índice de cámara promedio. However, neither works provide a close examination of their effectiveness for pricing implied policy paths or how closely they may describe actual monetary policy changes.

\section{METHODOLOGY}

\subsection{Extracting implied paths from swap contracts}

An interest rate swap (IRS) is a derivative contract in which two parties agree to exchange cash flows in the future. A plain vanilla IRS will settle for the accrued interests of a fixed rate and a floating rate. Chilean convention for interest rate swaps is based on an underlying index called índice de cámara promedio $(\mathrm{ICP})^{4}$ which compounds daily average interbank rates (TIB $)^{5}$ published daily by the Central Bank ${ }^{6}$. For our purposes, $I C P_{t}$ is the index published on day $t$ and the one day composition of ICP $\left(I C P_{t+1}\right)$ is obtained from TIBs daily in the following way:

4 Average swap index.

5 Average interbank rate - tasa interbancaria promedio.

6 If the interbank market does not show any transactions then MPR should be used. 


$$
I C P_{t+1}=I C P_{t}\left(1+T I B_{t} \times \frac{1}{360}\right)
$$

Expression 1 also refers to weekends and holidays, for which composition is linear ${ }^{7}$. Weekends affect composition positively (for positive rates), but account for minimal differences over a one year period on implicit rates (when rates are small). For the sake of simplicity, this article neglects such convention and thus, expression 1 can be written for any $\Delta$ number of days ${ }^{8}$ :

$$
I C P_{t+\Delta}=I C P_{t} \prod_{i=0}^{\Delta-1}\left(1+T I B_{t+i} \times \frac{1}{360}\right)
$$

Moreover, if the compounding factor $\left(T I B_{t}\right)$ is constant (and small), then expression 2 can be approximated by the following expression ${ }^{9}$ :

$$
I C P_{t+\Delta}=I C P_{t}(1+T I B)^{\frac{\Delta}{360}}
$$

which links the interbank rate to the projection of ICP. As described in Varela (2007) and Sotz and Alarcón (2007), the coupon of the floating leg of an IRS will accrue interests daily in accordance with the variation of ICP. In particular, the annualized nominal variation of ICP (TNA) 10 between any given time $t$ and $t+\Delta$ (TNAt, $t+\Delta$ ) is defined as:

$$
T N A_{t, t+\Delta}=\left(\frac{I C P_{t+\Delta}}{I C P_{t}}\right)^{\frac{360}{\Delta}}-1
$$

In fact, ICP is just the average geometric accrued interest of the floating leg of an IRS in pesos. In general, the value of an IRS at the time of its inception is 0 (in absence of transaction costs). Therefore, settlements for a plain zero coupon IRS depend on the difference between the variation of ICP (TNA) and the fixed leg rate.

7 For a weekend (3 days):

$$
I C P_{t+3}=I C P_{t}\left(1+T I B_{t} \times \frac{3}{360}\right)
$$

8 For the case of weekends, one could argue that a correction term could be included. The complexity lies in projecting ICP using two separate methods of composition, accounting for weekends and holidays

9 An informal but simple way to prove this is by taking logarithms as $T I B_{t}$ is a constant multiplied $\Delta$ times:

$$
\log \left(I C P_{t+\Delta}\right)=\log \left(I C P_{t}\right)+\frac{\Delta}{360} \times T I B_{t}
$$

which is equal to taking the logarithm of equation 3.

10 Tasa nominal anualizada. By convention, this rate is rounded to 4 decimal points. 
Thus, fixed rates correspond to the expected variation of TNA. It must therefore hold that for any given maturity $\Delta$, the value of a zero coupon IRS between a fixed rate $i$ and a floating rate TNA will be zero if and only if:

$$
I C P_{t}(1+i)^{\frac{\Delta}{360}}=I C P_{t}\left(1+T N A_{t, t+\Delta}\right)^{\frac{\Delta}{360}}
$$

Since, on average, the daily compounding factor of ICP is expected not to deviate from the Central Bank's MPR, it is possible to use expression 5 to extract the path of MPR that is implied in the swap curve between the nodes of meetings. Firstly, swap curves can be interpolated to obtain rates at maturities that correspond to monetary policy meetings. Secondly, expression 4 is used to obtain the implied rate between meetings. Thirdly, the rate between meetings can be rounded to the nearest quarter of a percentage point, corresponding to monetary policy conventions. This is interpreted as the implied MPR for that maturity.

The aforementioned methodology allows for a defined path of MPR between future monetary policy meetings, a set of implied rates that erase arbitrage for the derivative. Finally, implied probabilities can be obtained in a binary fashion by first, defining whether implied TNA is higher or lower than the previous implied MPR (suggesting a hike or cut in MPR), and then subtracting the rounded rate from the implied TNA and normalizing by a quarter of a percentage point. These probabilities are conditional to the whole path of MPR and cannot be interpreted on their own. The probability of the implied path of MPR is just the joint probability of each event.

Previous works in the topic provide a link between forward rates and MPR expectations (Sotz and Alarcón (2007)). In fact, equation 4 is a proxy for forward rates, and it accounts for the exact dates at which monetary policy meetings happen. Nonetheless in this article the term forward rate is not used as this methodology focuses on rounded rates between monetary policy meetings, instead of merely extracting the forward curve. This methodology relies strongly on the slope of swap curves. As a result, swap curves with positive slopes will generally yield implied MPR which are higher than current ones, and vice versa.

\subsubsection{Expected versus unexpected movements in the swap curve}

By setting a path for future interest rates (whether deterministic or based on its conditional probabilities) it is possible to project ICPs for any point in the future and calculate the arbitrage value of zero coupon swap rates at any point in the future using equations 4 and 5 .

To use conditional probabilities simply means using the same set of projected ICPs that are obtained from the zero coupon swap curve. On the other hand, a deterministic path for interest rates means projecting ICPs assuming that the most likely scenario at each node happens with absolute certainty. This is a useful risk analysis tool for 
practitioners. Furthermore, projecting swap rates in this way makes it possible to distinguish between movements based on changing expectations and the time decay of a swap contract.

\subsection{Example}

The methodology is best described by the following example. On October 20th 2015, the Central Bank's MPR was set at 3.25\%. The 3 month swap rate closed at $3.41 \%$ with maturity on January 22 nd 2016 , or 94 days ${ }^{11}$. The upcoming monetary policy meeting was scheduled for the 12th of November, 23 days further from our initial date, followed by December 17th, January 14th and February 11th, 114 days further.

In this scenario, although the floating leg pegged to the ICP is expected to compound at $3.25 \%$ (at the current MPR) for the first 23 days of the contract, the fixed rate would compound at $3.41 \%$ (our 3M swap rate) for 23 days, yielding an expected loss for the agent receiving the floating $\operatorname{leg}^{12}$. Further, the floating leg would certainly accrue a net loss for the life of the contract if the MPR remained unchanged between meetings. In this simple set up, implied hike expectations come into play, allowing for the possibility of changes in the upcoming four meetings to happen and even out the difference between the fixed and floating legs. The table below depicts the interpolated swap rates (between the current MPR and the 24 month zero coupon swap rate), implied ICP, TIB and MPRs:

\section{TABLE 1}

IMPLIED MPR FROM SWAP CURVE ON OCTOBER 20TH 2015.

\begin{tabular}{|c|c|c|c|c|c|}
\hline$\Delta$ Days & Date & $\begin{array}{c}\text { Swap } \\
\text { interpolation }\end{array}$ & ICP from swap & Implied TIB & Rounded MPR \\
\hline- & $10-20-2015$ & 3.25 & $16,687.85$ & 3.25 & 3.25 \\
23 & $11-12-2015$ & 3.29 & $16,721.98$ & 3.41 & 3.50 \\
58 & $12-17-2015$ & 3.35 & $16,776.63$ & 3.50 & 3.50 \\
86 & $01-14-2016$ & 3.40 & $16,821.52$ & 3.57 & 3.50 \\
114 & $02-11-2016$ & 3.44 & $16,867.49$ & 3.65 & 3.75 \\
\hline
\end{tabular}

If future TIBs were exactly what is implied in the swap curve then the value of both legs would be the same. Since MPR is set rounded to the nearest quarter of a percentage point, the difference between implied TIBs and the previous MPR may be

11 This is merely a result of conventions. A plain vanilla swap in CLP will start in $t+2$ working days.

12 Between the beginning of the contract and the first monetary policy meeting, ICP is expected to compound at the current MPR. 
interpreted as probabilities. For instance, the $3.41 \%$ implied TIB between November 12th and December 17th starting from a known 3.25\% MPR means that the probability of a hike on November 12 th is:

$$
\begin{aligned}
P(\text { Hike }) & =\frac{3.41 \%-3.25 \%}{0.25 \%} \\
& =65 \%
\end{aligned}
$$

The fact that MPRs can be increased, decreased or be maintained in each meeting is eluded by the direction the implied TIB follows, turning our scenario into a binomial problem which allows us to obtain the probability of keeping the rate unchanged ${ }^{13}$. The method can be used to recursively calculate the implied (conditional) probabilities of each MPR decision:

\section{TABLE 2}

IMPLIED MPRS AND PROBABILITIES ON OCTOBER 20TH 2015

\begin{tabular}{|r|c|c|c|c|c|c|c|c|}
\hline $\begin{array}{c}\Delta \\
\text { Days }\end{array}$ & Date & $\begin{array}{c}\text { Swap } \\
\text { interpolation }\end{array}$ & $\begin{array}{c}\text { Implied } \\
\text { TIB }\end{array}$ & $\begin{array}{c}\text { Rounded } \\
\text { MPR }\end{array}$ & $\begin{array}{c}\text { Actual } \\
\text { MPR }\end{array}$ & $\begin{array}{c}\text { P } \\
\text { (decrease) }\end{array}$ & $\begin{array}{c}\text { P } \\
\text { (maintain) }\end{array}$ & P (hike) \\
\hline 0 & $10-20-2015$ & 3.25 & 3.25 & 3.25 & 3.25 & & & \\
23 & $11-12-2015$ & 3.29 & 3.41 & 3.50 & 3.25 & $0 \%$ & $35 \%$ & $65 \%$ \\
58 & $12-17-2015$ & 3.35 & 3.50 & 3.50 & 3.50 & $0 \%$ & $100 \%$ & $0 \%$ \\
86 & $01-14-2016$ & 3.40 & 3.57 & 3.50 & 3.50 & $0 \%$ & $72 \%$ & $28 \%$ \\
114 & $02-11-2016$ & 3.44 & 3.65 & 3.75 & 3.50 & $0 \%$ & $40 \%$ & $60 \%$ \\
\hline
\end{tabular}

Finally, the likelihood of occurrence of that particular MPR path is the joint probability of each decision. In this case, the probability of a hike and then maintaining the rate twice, or:

$$
\begin{aligned}
P(\text { path }) & =65 \% \times 100 \% \times 72 \% \\
& =47 \%
\end{aligned}
$$

which is also interpreted as the likelihood of the swap being worth 0 at maturity. In this scenario, if the MPR remained unchanged until December 17th then it would compound to $16,774.06$, and if there was a $25 \mathrm{bp}$ hike on November 12 th then it would compound to 16,778 , which means that:

13 This simplification allows to neglect the likelihood of two equally likely movements of a $25 \mathrm{bp}$ hike and a cut that yield a Obp change 
$E_{t}\left(I C P_{t+58}\right)=P($ Hike $) \times I C P_{\text {Hike }}+P($ Maintain $) \times I C P_{\text {Maintain }} E_{t}\left(I C P_{t+58}\right)=65 \% \times$ $16,778+35 \% \times 16,774.06$

$$
=16,776.63
$$

this is exactly the ICP we would obtain from interpolating the zero coupon swap curve. The actual path of MPR was:

TABLE 3

IMPLIED MPRS AND PROBABILITIES ON OCTOBER 20TH 2015

\begin{tabular}{|r|c|c|c|c|c|}
\hline Days & Date & Rounded MPR & Actual MPR & P (maintain) & P (hike) \\
\hline 0 & $10-20-2015$ & 3.25 & 3.25 & $100 \%$ & $0 \%$ \\
23 & $11-12-2015$ & 3.50 & 3.25 & $35 \%$ & $65 \%$ \\
58 & $12-17-2015$ & 3.50 & 3.50 & $100 \%$ & $0 \%$ \\
86 & $01-14-2016$ & 3.50 & 3.50 & $72 \%$ & $28 \%$ \\
114 & $02-11-2016$ & 3.75 & 3.50 & $40 \%$ & $60 \%$ \\
149 & $03-17-2016$ & 3.75 & 3.50 & $96 \%$ & $0 \%$ \\
175 & $04-12-2016$ & 3.75 & 3.50 & $92 \%$ & $8 \%$ \\
210 & $05-17-2016$ & 3.75 & 3.50 & $68 \%$ & $32 \%$ \\
240 & $06-16-2016$ & 4.00 & 3.50 & $40 \%$ & $60 \%$ \\
268 & $07-14-2016$ & 4.00 & 3.50 & $56 \%$ & $0 \%$ \\
296 & $08-11-2016$ & 4.00 & 3.50 & $60 \%$ & $0 \%$ \\
331 & $09-15-2016$ & 4.00 & 3.50 & $84 \%$ & $0 \%$ \\
364 & $10-18-2016$ & 4.00 & 3.50 & $84 \%$ & $0 \%$ \\
394 & $11-17-2016$ & 4.00 & 3.50 & $88 \%$ & $0 \%$ \\
420 & $12-13-2016$ & 4.00 & 3.50 & $92 \%$ & $8 \%$ \\
457 & $01-19-2017$ & 4.00 & 3.25 & $84 \%$ & $16 \%$ \\
483 & $02-14-2017$ & 4.00 & 3.25 & $64 \%$ & $36 \%$ \\
513 & $03-16-2017$ & 4.00 & 3.00 & $52 \%$ & $48 \%$ \\
\hline
\end{tabular}

On November 12th, contrary to what derivatives priced 23 days before, the monetary policy rate was kept unchanged. Since hikes happened less often than what was priced in the three month rate, the payer of the floating leg ended up paying a TNA of $3.40 \%$, or $1 \mathrm{bp}$ lower than what was received. The rest of the swap curve was also more hawkish about the next 15 months, where monetary policy rates were expected to reach a terminal level of around $4 \%$. Instead, the Central Bank cut rates to $2.50 \%$ after many months of economic slack and low inflation. This would have seemed odd to an investor that had observed average rates of $3.98 \%$ since $2008^{14}$.

14 Including a 10 month period of rates at $0.5 \%$ in 2009. 


\subsection{Expected swap rates}

As described before, on October 20th the 3 month swap rate was 3.41\%. According to the path of interest rates that included one hike in the meeting of November 12th, the rate with the same maturity as the original contract should increase by 5 bp by October 30th merely because of the number of days that have passed. The standard 3 month contract should increase by $10 \mathrm{bp}$ as it compounds 10 more days with a $25 \mathrm{bp}$ higher rate.

Contrary to what was priced, the actual 3 month rate on that date was $3.40 \%$, indicating that interest rates did not increase in the way it was priced. This can be interpreted as the likelihood of a hike in November falling (below 50\%, in fact). To an observer who is not calculating these likelihoods, it may seem as if the market did not modify its view when in fact it changed dramatically. This simple example shows the importance of this methodology.

In the next section the following questions are addressed; how often do investors lose when betting on a MPR path? How does the market react when it fails to predict a change in monetary policy? If market participants are unable to properly price future paths of MPR, is there a specific direction for these errors? Can this methodology be used to extract measures of term premiums? And finally, can such term premiums be quantified in order to better understand the transmission of monetary policy?

\section{DATA AND RESULTS}

With the aforementioned methodology, it is possible to extract implied monetary policy rate paths using daily closings for the swap curve and the known dates of central bank meetings. Accordingly, it is also possible to obtain the probability of hikes, analyze the dynamics of expectations, the degree of response of MPR expectations to relevant information and assess the overall predictive power of the swap curve to MPR decisions.

Ex-post known meeting dates can be used without loss of generality since their monthly frequency has been consistent. In this section, daily observations between January 2011 and August 2017 for the zero coupon swap curve at maturities of 3, 6, 9, 12 and 18 months are used, as well as actual monetary policy rates in order to compare 15 months ahead implied rates. The choice of ending the sample in September 2017 is due to the change in the frequency of policy meetings from 12 to 8 starting in 2018. The would-have-been future monthly dates of meetings up to August 2017 is estimated following historical dates for monetary policy meetings.

\subsection{Swap curves between 2011 and 2017}

Table 4 summarizes daily swap and monetary policy rates between 2011 and 2017. It also shows the average difference between 18 month swaps and MPRs, as well as their standard deviations. One and a half year swap rates tend to be higher than 
MPRs by an average of $8 \mathrm{bps}$. In three out of seven years, average swap rates showed an upward slope, with an average difference of $33 \mathrm{bps}$. In the four years of negative slopes, two of them constitute the highest average MPRs in the sample (suggesting a period of tightening monetary policy). Since zero coupon swap rates refer to implied future policy rates, average differences are interpreted as pure term premiums. Such premiums' variability is constant over the sample, with the exception of 2011. If instead of the 18 month rate the 24 month zero coupon rate is used results are similar.

\section{FIGURE 1}

SWAP CURVES BETWEEN JANUARY 2011 AND DECEMBER 2017
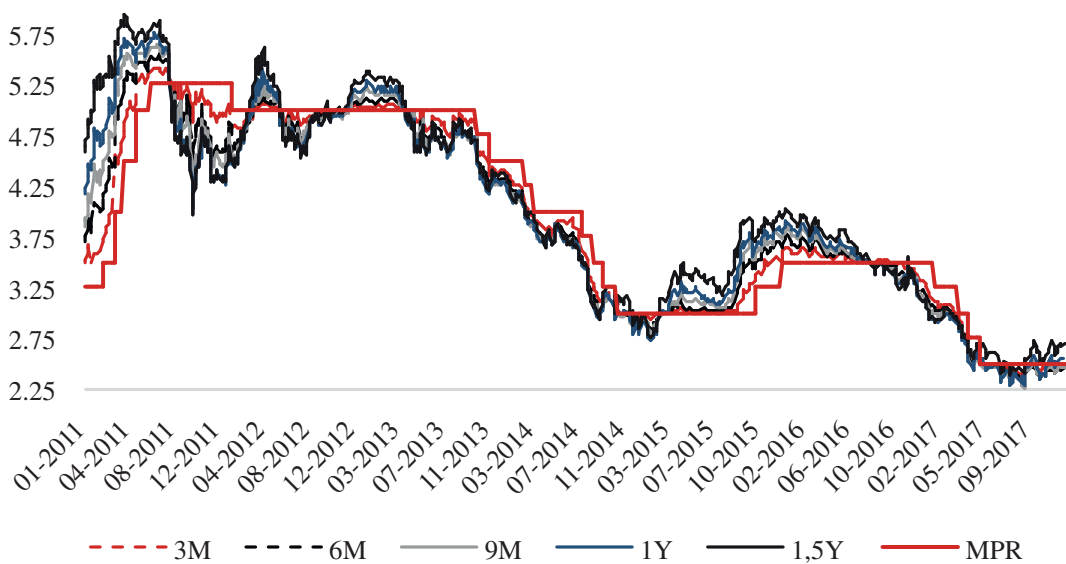

TABLE 4

SUMMARY OF AVERAGE POLICY AND SWAP RATES BETWEEN 2011 AND 2017

\begin{tabular}{|c|c|c|c|c|c|c|c|c|}
\cline { 2 - 8 } \multicolumn{1}{c|}{} & MPR & $3 \mathrm{M}$ & $6 \mathrm{M}$ & $9 \mathrm{M}$ & $12 \mathrm{M}$ & $18 \mathrm{M}$ & $18 \mathrm{M}-\mathrm{MPR}$ & $\begin{array}{c}\text { SD } \\
(18 \mathrm{M}-\mathrm{MPR})\end{array}$ \\
\hline 2011 & 4.68 & 4.83 & 4.89 & 4.95 & 5.00 & 5.15 & 0.47 & 1.08 \\
2012 & 5.01 & 4.96 & 4.93 & 4.92 & 4.92 & 4.97 & -0.03 & 0.30 \\
2013 & 4.92 & 4.85 & 4.79 & 4.77 & 4.77 & 4.82 & -0.10 & 0.27 \\
2014 & 3.74 & 3.60 & 3.52 & 3.50 & 3.49 & 3.54 & -0.21 & 0.18 \\
2015 & 3.06 & 3.14 & 3.21 & 3.26 & 3.32 & 3.46 & 0.40 & 0.28 \\
2016 & 3.50 & 3.53 & 3.53 & 3.54 & 3.56 & 3.61 & 0.11 & 0.25 \\
2017 & 2.73 & 2.64 & 2.60 & 2.58 & 2.59 & 2.68 & -0.05 & 0.20 \\
\hline Total & 3.95 & 3.93 & 3.92 & 3.93 & 3.95 & 4.03 & 0.08 & 0.53 \\
\hline
\end{tabular}




\subsection{Monetary policy rates and average interbank rates}

For a better characterization of monetary policy cycles and their effect on implied MPR paths it is convenient to study past policy. Between 2007 and 2017, monetary policy target rates achieved their maximum and minimum levels both before and after the global economic downturn of 2008 and 2009 (Figure 2). Target rates average $3.95 \%$ with a median of $4 \%$ and they have stayed between $2.50 \%$ and $6.50 \%$ over $80 \%$ of the time. During our sample period of 2011 to 2017, MPRs were always bounded by those limits.

\section{FIGURE 2}

\section{MONETARY POLICY RATES AND AVERAGE INTERBANK RATES}
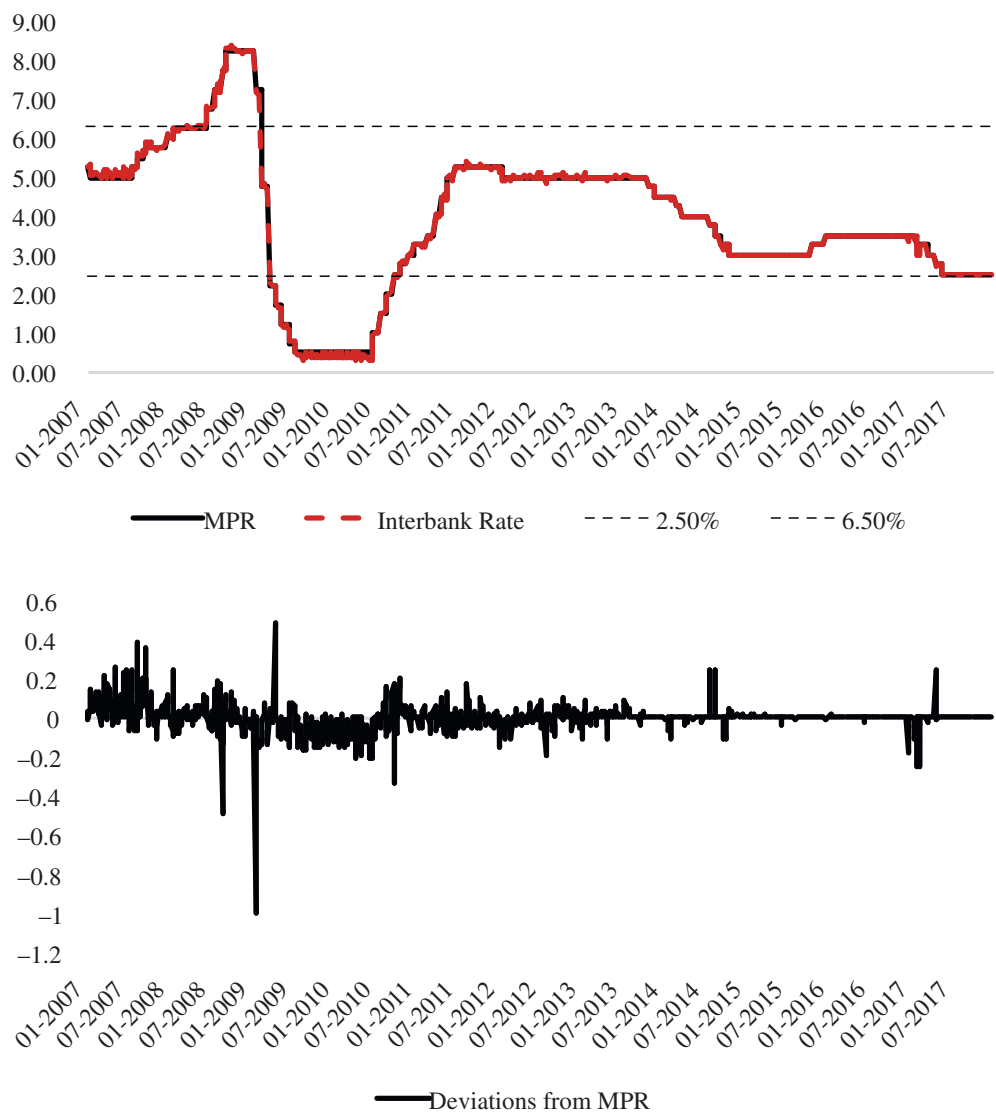
Our sample period of 2011 to 2017 shows an increase of MPR from $3.25 \%$ to $5.25 \%$, following repeated hikes since the near zero levels of 2009. Between 2011 and 2013, MPR was kept between 5\% and 5.25\% for a total of 900 days, after which MPR was cut to levels that average $3.30 \% 15$. In fact, both during 2015, and since 2017, monetary policy has been expansionary, keeping MPR at 3\% for one year in the period between October 2014 and October 2015, and at $2.50 \%$ for the second half of $2017^{16}$. Between 2011 and 2017, 20 changes in MPR have taken place, 17 of which were of a 25bp magnitude, seven of which have been hikes (including three hikes of 50bps), and 13 have been cuts (all of them of $25 \mathrm{bps}$ ). Table 5 shows that cuts are more common than hikes (even if hikes of 50bps are counted twice), reflecting the expansionary nature of the sample period. Accordingly, 2011 and 2015 are years of at least partially tightening monetary policy given that hikes took place then, whereas the rest are years of looser monetary policy.

\section{TABLE 5}

MONETARY POLICY MEETINGS BETWEEN 2011 AND 2017

\begin{tabular}{|c|c|c|c|c|}
\cline { 2 - 5 } \multicolumn{1}{c|}{} & \multicolumn{4}{c|}{ Number of times the CB acted } \\
\cline { 2 - 5 } \multicolumn{1}{c|}{} & Cut & Keep & Hike & MPM \\
\hline 2011 & 0 & 7 & 5 & 12 \\
2012 & 1 & 11 & 0 & 12 \\
2013 & 2 & 10 & 0 & 12 \\
2014 & 6 & 6 & 0 & 12 \\
2015 & 0 & 10 & 2 & 12 \\
2016 & 0 & 12 & 0 & 12 \\
2017 & 4 & 8 & 0 & 12 \\
\hline Total & 13 & 64 & 7 & 84 \\
\hline
\end{tabular}

With respect to índice de cámara promedio, daily interbank rates (TIB) average no statistically significant deviations from monetary policy rates. Such differences have in fact grown smaller since $2013^{17}$. Finally, the Central Bank tends to provide forward guidance and policy cycles should be, to some extent, expected by market participants. As it will be shown, MPR paths do depend on the current cycle of

15 This hike cycle coincides with the higher variability of the premium of 18 month swaps compared to policy rates.

16 And until October 2018 when the target rate was moved to $2.75 \%$.

17 The Chilean market for interbank loans usually trades at the target rate since 2014, only deviating in very few occasions. Most liquidity traders do not see value in deviating from the target rate. 
monetary policy. With respect to the ultimate goal of monetary policy, inflation has mostly stayed anchored to its 3\% target since 2011.

\subsection{Implied monetary policy rate paths}

In this section daily implied monetary policy paths between 2011 and August 2017 are calculated. From Table 4, it is expected that positive average term premiums would yield upward sloping MPR paths, but with varying levels for terminal rates at 18 months. Figure 3 shows that average implied rates have an upward slope at maturities over 6 months, suggesting that policy cuts are only priced for the near horizon. This is sensible given that most of the sample was taken in a generally expansionary cycle of monetary policy (3M swap rates were lower than MPRs $60 \%$ of the time, and are 2bps lower on average).

On the other hand, average fifteen month ahead implied MPRs are higher than actual target rates, corresponding to the higher average levels of $18 \mathrm{M}$ swaps. The expansionary nature of monetary policy during the sample period is also shown by the fact that 18M swaps are lower than MPRs 51\% of the time, suggesting that when priced in, implied hike paths would be steep. In fact, the change in the one month premium has a positive slope (Figure 4).

FIGURE 3

UPWARD SLOPING AVERAGE IMPLIED MONETARY POLICY RATES

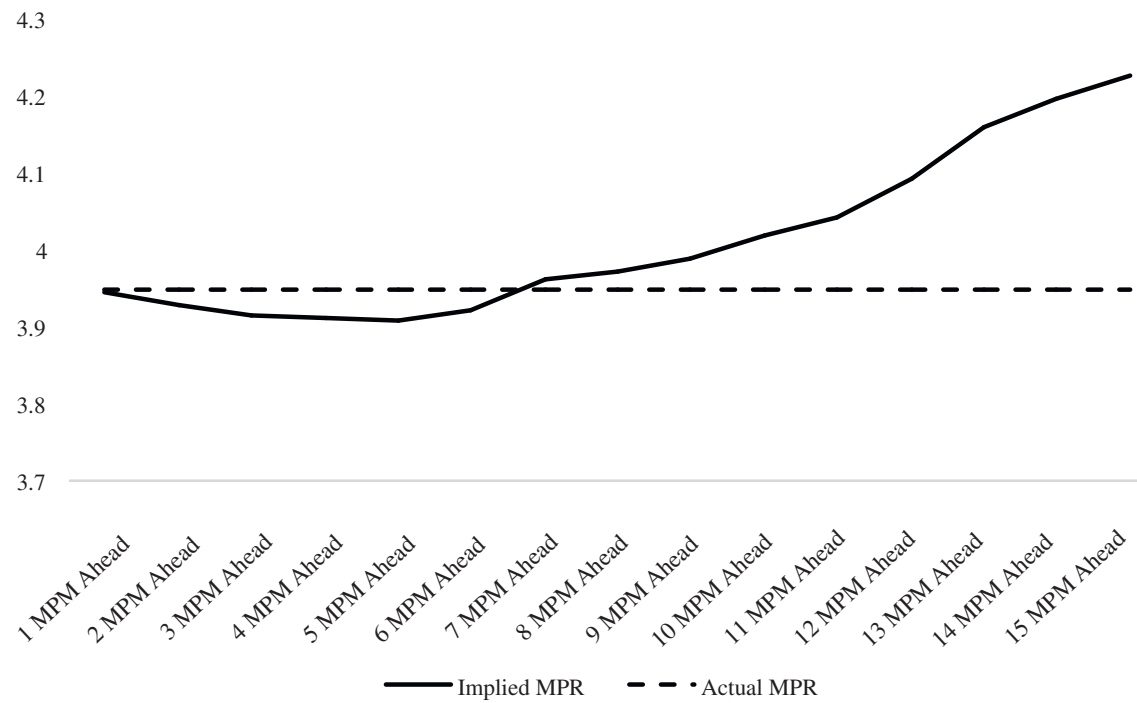


FIGURE 4

\section{AVERAGE SLOPE OF IMPLIED MONETARY POLICY RATES BETWEEN MEETINGS}

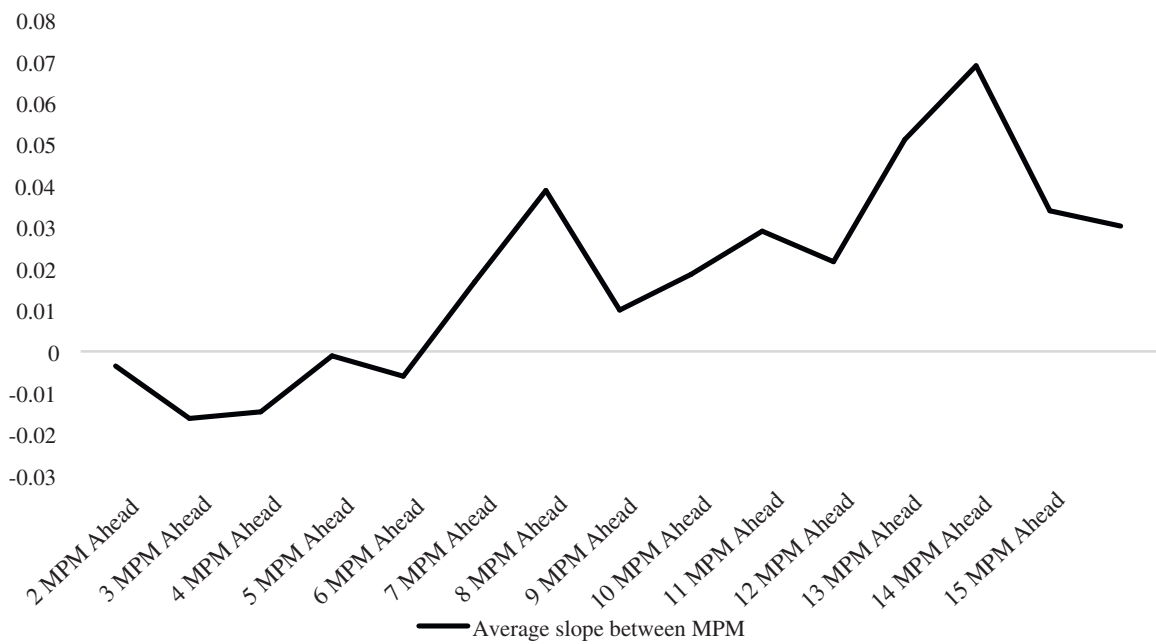

TABLE 6

AVERAGE NUMBER OF IMPLIED HIKES/CUTS BETWEEN 2011 AND 2017 (15 MONTHS AHEAD)

\begin{tabular}{|c|c|c|c|}
\cline { 2 - 4 } \multicolumn{1}{c|}{} & \multicolumn{3}{c|}{ Average number of hikes/cuts } \\
\cline { 2 - 4 } \multicolumn{1}{c|}{} & Cut cycle & Whole series & Hike cycle \\
\hline 2011 & -3.1 & 3.1 & 7.1 \\
2012 & -1.6 & 0.3 & 1.3 \\
2013 & -1.2 & 0.0 & 1.0 \\
2014 & -1.3 & -0.4 & 0.5 \\
2015 & -1.0 & 2.8 & 2.9 \\
2016 & -1.1 & 0.8 & 1.3 \\
2017 & -1.2 & 0.0 & 0.6 \\
\hline All & -1.5 & 0.9 & 2.1 \\
\hline
\end{tabular}

Table 6 represents hikes with a positive sign and cuts with a negative sign. The average number of hikes fifteen months ahead is 0.9 and it is only negative in one year of the sample, whereas the number reaches 2.1 during hike only cycles ${ }^{18}$. On the

18 According to the implied rate one meeting ahead, ie. if the likelihood of a hike/cut is higher than $50 \%$. 
other hand, an average of 1.5 cuts were priced in, regardless of the fact that monetary policy was expansive more often than it was contractive. In the tightening years of 2011 and 2015, implied MPRs were priced accordingly, but the same cannot be said of the rest. In fact, as Table 7 shows, the upward sloping term structure of implied rates is almost always positive (the average slope of $15 \mathrm{MPM}$ ahead rates is $25 \mathrm{bps}$ ), while standard deviations of implied MPR paths are roughly equal for longer maturities. This suggests that all variability in the level of implied rates is due to variability in the front end of the curve. Further, in our sample, implied policy rates oscillate around the moving average mean of MPRs since 2007, reinforcing that medium term implied rates depend more on spot rates rather than policy cycles (Figure 5).

\section{FIGURE 5}

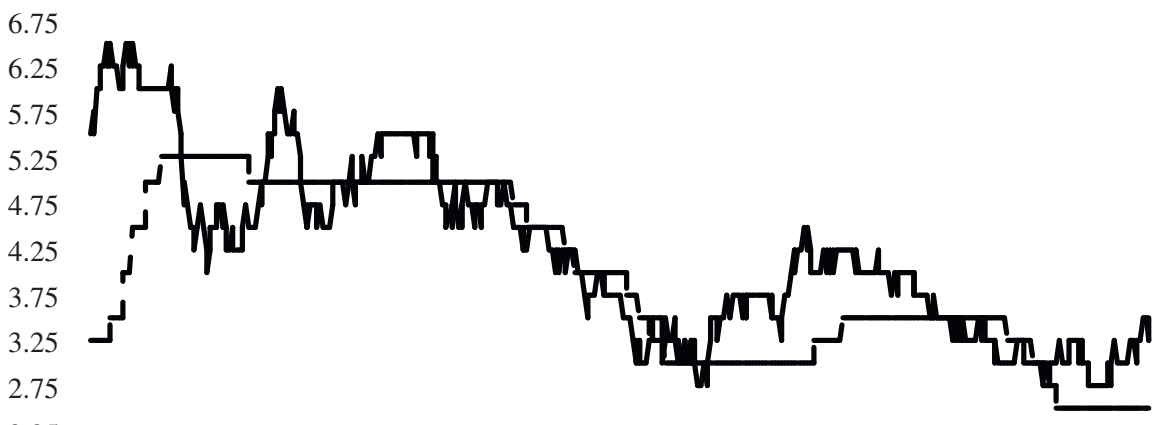

2.25

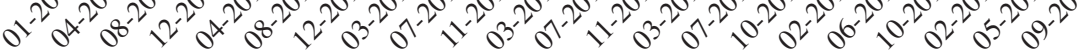

15MPM implied rate $\quad-\quad-$ MPR

Implied future rates show persistence and they are anchored to current rates. Table 8 shows that there is a positive correlation between overnight current MPRs and future ones (the average level of MPR and 15 month ahead implied rates show a correlation of 0.96). This means that periods of high average monetary policy rates such as 2011 and 2012 exhibit higher implied terminal rates, and periods of low inflation and low rates like 2016 and 2017 show lower terminal rates.

In our sample, hike and cut cycles are persistent and a hike is more likely after one has taken place (Table 5 shows that cuts and hikes "cluster"). As seen before, 
not all monetary policy cycles are the same, and often the level of implied terminal rates depends on forward guidance and changing macroeconomic dynamics. The "scenario" variable in Table 9 assigns a 1 to expected hikes, a -1 to cuts and a 0 when rates are expected to remain unchanged ${ }^{19}$. The table suggests that there is a positive correlation between current policy cycles and the path of implied future rates, and that average accumulated month to month premiums are higher for more hawkish scenarios and vice versa.

The fact that some periods show higher term premiums, and that average implied rates differ greatly from actual policy rates, suggests that extracting policy paths from swap curves is an ineffective tool. Fifteen month ahead implied rates are dependent on the level of current MPR, and not on expectations for the economic cycle. If implicit monetary policy rates are unbiased and merely the result of market expectations, then average implicit rates should not differ much from actual rates, even if the shape of their path does not correspond to actual future events. Instead, we see a premium between medium and short term implied rates.

Monetary policy decisions are taken on the basis of price stability pursuing an inflation target of $3 \%$ but past inflation history shows a high degree of reversion towards the $\mathrm{CB}$ target, and so do actual monetary policy rates, reverting towards lower levels as inflation approaches its target. Evidence has been shown to support that the opposite happens with implied policy paths as medium term rates co-move with current MPR cycles, instead of showing pure expectations.

\subsection{Implied probabilities one meeting ahead}

Implied probabilities also matter since the slope of the curve will affect not only terminal rates but also the likelihood of each scenario. The monetary policy meeting regime remained unchanged in its monthly frequency until the end of 2017, allowing for the use of the full sample of 2017 rates. On the day of monetary policy meeting, only 5 times in 2011 and 2 times in 2014 was the Central Bank expected to do something other than keeping their target rate unchanged. Table 10 shows the average probability of monetary policy changes of $25 \mathrm{bps}$ on each day of monetary policy meetings given the most likely scenario. As seen on the under-representation of the number of times the market priced hikes/cuts and their likelihood compared to keeping rates unchanged, the market is more decisive at pricing hikes than cuts, and certainly more decisive at pricing that rates will remain unchanged. This means that the market was incorrect even when pricing the next policy decision since changes happened more often than what was priced.

19 In the next policy meeting 

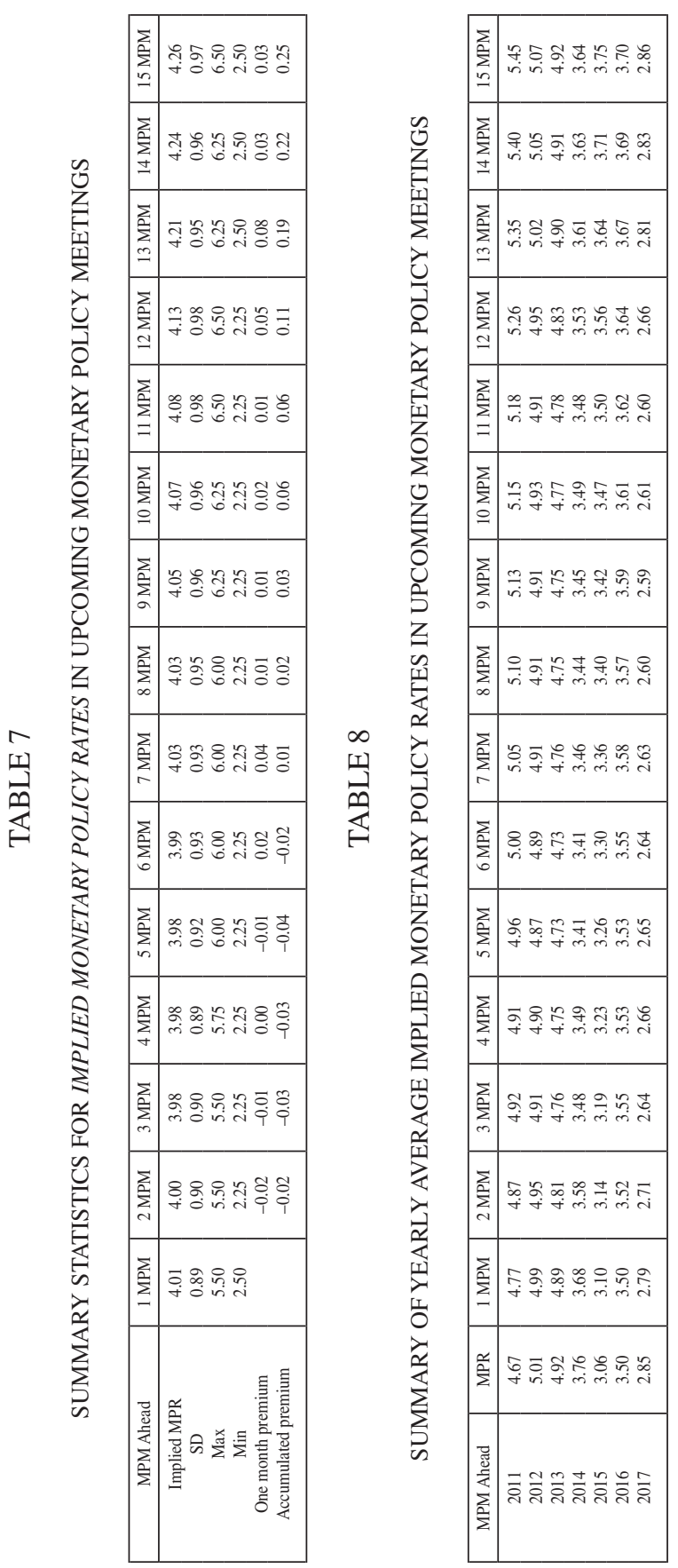

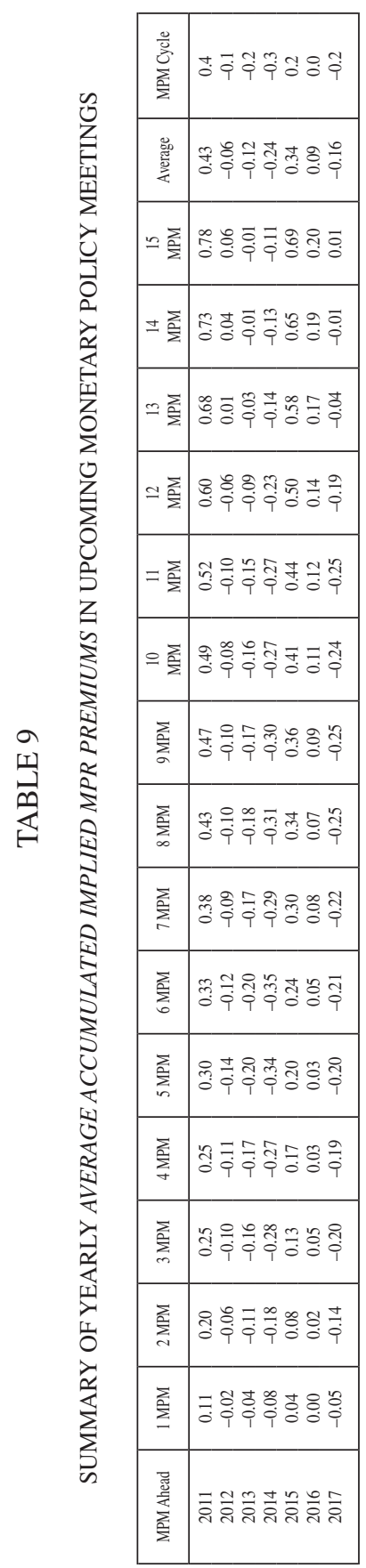


TABLE 10

AVERAGE IMPLIED PROBABILITY OF CUTS AND HIKES ON THE DAY OF EACH MONETARY POLICY MEETING

\begin{tabular}{|c|c|c|c|c|c|c|}
\cline { 2 - 7 } \multicolumn{1}{c|}{} & \multicolumn{3}{c|}{$\begin{array}{c}\text { Number of times the CB } \\
\text { was expected to act }\end{array}$} & \multicolumn{3}{c|}{ Implied probabilities } \\
\cline { 2 - 7 } \multicolumn{1}{c|}{} & Cut & Maintain & Hike & Cut & Maintain & Hike \\
\hline 2011 & 0 & 7 & 5 & & $75 \%$ & $69 \%$ \\
2012 & 0 & 12 & 0 & & $90 \%$ & \\
2013 & 0 & 12 & 0 & & $86 \%$ & \\
2014 & 2 & 10 & 0 & $56 \%$ & $76 \%$ & \\
2015 & 0 & 12 & 0 & & $87 \%$ & \\
2016 & 0 & 12 & 0 & & $91 \%$ & \\
2017 & 0 & 12 & 0 & & $84 \%$ & \\
\hline
\end{tabular}

In fact, Table 11 shows that almost every time rates were changed (with the exception of 2011), the market was surprised by the decision taken by the Central Bank.

Implied changes in the target rate for the upcoming meeting are strictly governed by the $3 \mathrm{M}$ swap rate, a rather illiquid contract in nature. Going back to Table $4,3 \mathrm{M}$ rates are very close in level to monetary policy rates, indicating that implied changes would be rare. However, illiquidity is not enough to explain the inability of the $3 \mathrm{M}$ contract to properly price policy decisions, especially since rates are interpolated in absence of actual transactions, and therefore should reflect prices more accurately through contracts with longer maturities. Moreover, 3M swaps are generally used as benchmarks (and hedges) for more actively traded securities such as bank deposits or currency forwards.

\section{TABLE 11}

AVERAGE IMPLIED PROBABILITY OF CUTS AND HIKES WHEN THE CENTRAL BANK ACTED

\begin{tabular}{|c|c|c|c|c|c|c|}
\cline { 2 - 7 } \multicolumn{1}{c|}{} & \multicolumn{3}{c|}{ Policy decisions } & \multicolumn{3}{c|}{ Implied probabilities } \\
\cline { 2 - 7 } \multicolumn{1}{c|}{} & Cut & Maintain & Hike & Cut & Maintain & Hike \\
\hline 2011 & 0 & 7 & 5 & & $74 \%$ & $66 \%$ \\
2012 & 1 & 11 & 0 & $28 \%$ & $92 \%$ & \\
2013 & 2 & 10 & 0 & $18 \%$ & $86 \%$ & \\
2014 & 6 & 6 & 0 & $44 \%$ & $85 \%$ & \\
2015 & 0 & 10 & 2 & & $91 \%$ & $32 \%$ \\
2016 & 0 & 12 & 0 & & $91 \%$ & \\
2017 & 4 & 8 & 0 & $34 \%$ & $93 \%$ & \\
\hline
\end{tabular}


In short, the inability of the curve to anticipate policy changes should not be attributed to the illiquidity of the short end of the curve. In fact, the findings in this section correspond to those of the previous one. The over representation of hikes has to do with the slope of the curve which is generally positive, and the underrepresentation of cuts corresponds to a period of monetary policy that repeatedly became more expansive. Similarly, findings for longer implied rates also suggest that they exceed actual rates, supporting the idea that there is, in fact, a premium in implied rates from actual monetary policy. In the next section, those term premiums will be quantified.

\section{BACKTESTING AND DYNAMICS OF IMPLIED RATES}

Implied paths can be tested against actual policy rates. In this section, we turn back to the shortened sample (up to August 2017). As suggested, implied rates are on average different (higher), from actual rates. A pricing error is defined as the difference between the actual rate that was implicit for any given date and the actual rate.

Table 12 shows yearly average pricing errors. Absolute one to eight month ahead errors are close to zero whereas for longer maturities they increase. In fact, for all seven years of the sample, average pricing errors for maturities longer than 12 months are strictly negative. This means that the market overpriced the implied path MP would take. On average, the market mispriced implied 15 month ahead rates by 66bps, reaching maximums of 200bps in September 2013 when the market failed to price that MPRs would fall from 5\% to $3 \%$. Correlation between MPRs and pricing errors is -0.84 , meaning that higher rates lead to higher errors, which is consistent with the fact that average terminal rates differ from average actual rates. In short, the market prices poorly the future path MPR will take, so poorly that implied paths do not even correlate with historical information of policy rates.

Errors for up to $8 \mathrm{MPM}$ ahead are small regardless of how poorly the market prices one meeting ahead decisions. This is explained by the fact that for most of the time, rates remain unchanged, and that when surprised, the market adapts its view to new information.

Table 13 shows all monetary policy meetings between 2011 and August 2017, as well as the spot implied MPR one meeting ahead and their implied probabilities. Surprises are marked with a 1 when actual policy decisions were different than what was priced in. The change in probabilities refers to the difference in the probability of maintaining MPR between the following and the current meeting, after a surprise happened.

When the market is surprised, one of two things happens; either swap rates react to the surprise by shifting to a new level, or by increasing the likelihood of any given movement. In most cases, implied probabilities jump to adapt new information. 


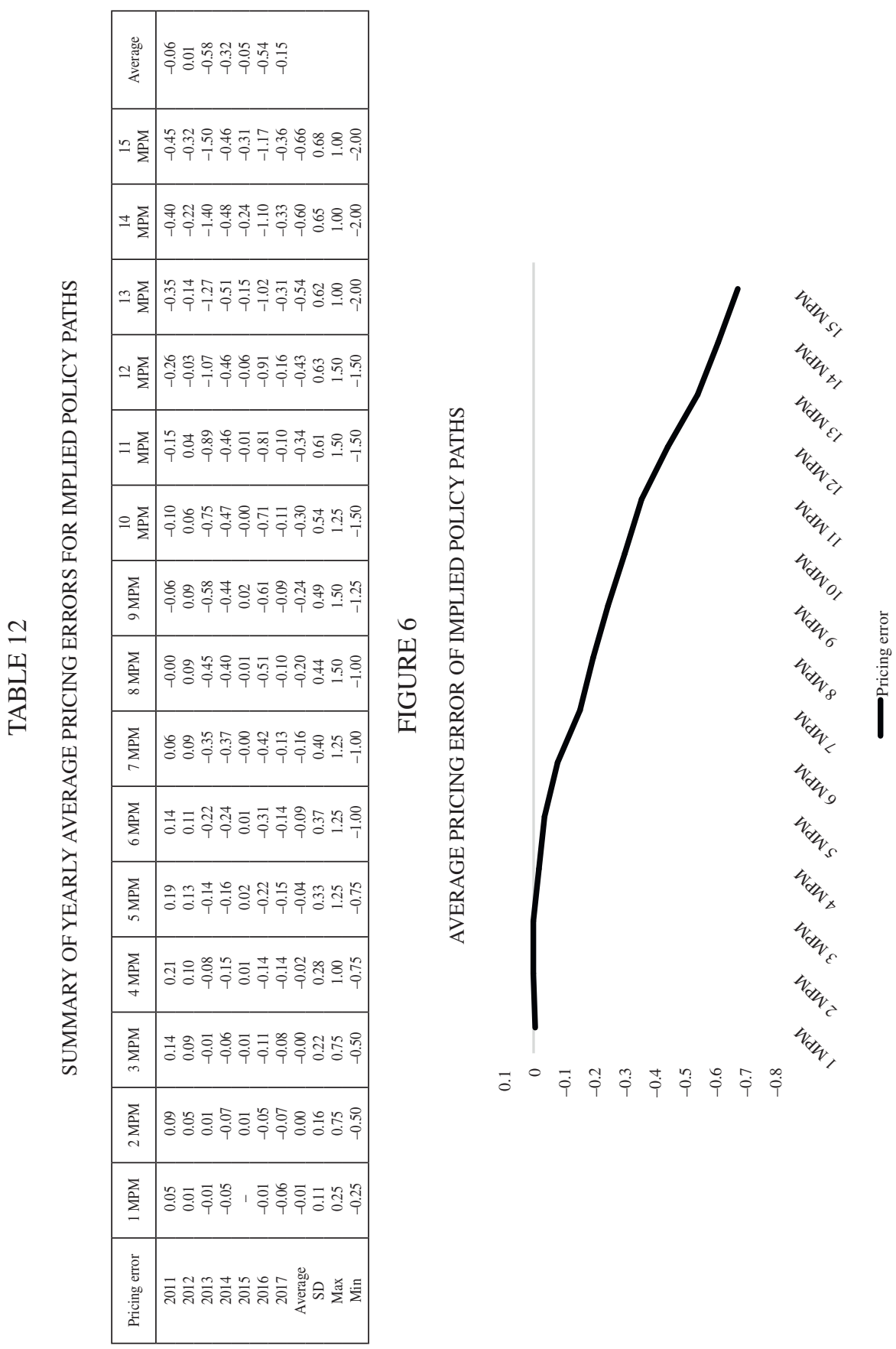




\section{TABLE 13}

\section{MONETARY POLICY DECISIONS AND THEIR PROBABILITIES}

\begin{tabular}{|c|c|c|c|c|c|c|c|c|}
\hline & \multicolumn{3}{|c|}{ Monetary policy decisions } & \multicolumn{3}{|c|}{ Probabilities } & \multicolumn{2}{|c|}{ Surprise measures } \\
\hline & $\begin{array}{c}\text { MPR (bef. } \\
\text { MPM) }\end{array}$ & $\begin{array}{c}\text { Implied } \\
\text { MPR (av.) }\end{array}$ & $\begin{array}{c}\text { Actual } \\
\text { decision }\end{array}$ & Cut & Maintain & Hike & Surprise & $\begin{array}{l}\text { Change in } \\
\text { probs }(\%)\end{array}$ \\
\hline 01-13-2011 & 3.25 & 3.50 & 3.25 & - & 44 & 56 & 1 & 0 \\
\hline $02-17-2011$ & 3.25 & 3.50 & 3.50 & - & 44 & 56 & - & \\
\hline 03-17-2011 & 3.50 & 3.75 & 4.00 & - & 40 & 60 & 1 & 40 \\
\hline $04-12-2011$ & 4.00 & 4.25 & 4.50 & - & 0 & 100 & 1 & -28 \\
\hline 05-12-2011 & 4.50 & 4.75 & 5.00 & - & 28 & 72 & 1 & -28 \\
\hline 06-14-2011 & 5.00 & 5.00 & 5.25 & - & 56 & 44 & 1 & -24 \\
\hline 07-14-2011 & 5.25 & 5.25 & 5.25 & - & 80 & 20 & - & \\
\hline $08-18-2011$ & 5.25 & 5.25 & 5.25 & 12 & 88 & - & - & \\
\hline 09-15-2011 & 5.25 & 5.25 & 5.25 & 4 & 96 & - & - & \\
\hline $10-13-2011$ & 5.25 & 5.25 & 5.25 & 24 & 76 & - & - & \\
\hline $11-15-2011$ & 5.25 & 5.25 & 5.25 & 24 & 76 & - & - & \\
\hline $12-13-2011$ & 5.25 & 5.25 & 5.25 & 44 & 56 & - & - & \\
\hline $01-12-2012$ & 5.25 & 5.25 & 5.00 & 28 & 72 & - & 1 & 0 \\
\hline 02-14-2012 & 5.00 & 5.00 & 5.00 & 28 & 72 & - & - & \\
\hline $03-15-2012$ & 5.00 & 5.00 & 5.00 & - & 96 & 4 & - & \\
\hline $04-17-2012$ & 5.00 & 5.00 & 5.00 & - & 92 & 8 & - & \\
\hline $05-17-2012$ & 5.00 & 5.00 & 5.00 & 4 & 96 & - & - & \\
\hline 06-14-2012 & 5.00 & 5.00 & 5.00 & 12 & 88 & - & - & \\
\hline $07-12-2012$ & 5.00 & 5.00 & 5.00 & 24 & 76 & - & - & \\
\hline 08-16-2012 & 5.00 & 5.00 & 5.00 & 4 & 96 & - & - & \\
\hline 09-13-2012 & 5.00 & 5.00 & 5.00 & - & 100 & - & - & \\
\hline $10-18-2012$ & 5.00 & 5.00 & 5.00 & - & 100 & - & - & \\
\hline $11-13-2012$ & 5.00 & 5.00 & 5.00 & 4 & 96 & - & - & \\
\hline $12-13-2012$ & 5.00 & 5.00 & 5.00 & - & 96 & 4 & - & \\
\hline $01-17-2013$ & 5.00 & 5.00 & 5.00 & - & 96 & 4 & - & \\
\hline $02-14-2013$ & 5.00 & 5.00 & 5.00 & - & 96 & 4 & - & \\
\hline $03-14-2013$ & 5.00 & 5.00 & 5.00 & - & 96 & 4 & - & \\
\hline $04-11-2013$ & 5.00 & 5.00 & 5.00 & - & 96 & 4 & - & \\
\hline $05-16-2013$ & 5.00 & 5.00 & 5.00 & 16 & 84 & - & - & \\
\hline $06-13-2013$ & 5.00 & 5.00 & 5.00 & 24 & 76 & - & - & \\
\hline $07-11-2013$ & 5.00 & 5.00 & 5.00 & 16 & 84 & - & - & \\
\hline 08-13-2013 & 5.00 & 5.00 & 5.00 & 24 & 76 & - & - & \\
\hline 09-12-2013 & 5.00 & 5.00 & 5.00 & 16 & 84 & - & - & \\
\hline $10-17-2013$ & 5.00 & 5.00 & 4.75 & 12 & 88 & - & 1 & 12 \\
\hline $11-19-2013$ & 4.75 & 4.75 & 4.50 & 24 & 76 & - & 1 & 0 \\
\hline $12-12-2013$ & 4.50 & 4.50 & 4.50 & 24 & 76 & - & - & \\
\hline $01-16-2014$ & 4.50 & 4.50 & 4.50 & 28 & 72 & - & - & \\
\hline $02-18-2014$ & 4.50 & 4.50 & 4.25 & 32 & 68 & - & 1 & 12 \\
\hline 03-13-2014 & 4.25 & 4.25 & 4.00 & 44 & 56 & - & 1 & -24 \\
\hline $04-17-2014$ & 4.00 & 4.00 & 4.00 & 20 & 80 & - & - & \\
\hline $05-15-2014$ & 4.00 & 4.00 & 4.00 & 12 & 88 & - & - & \\
\hline 06-12-2014 & 4.00 & 4.00 & 4.00 & 16 & 84 & - & - & \\
\hline $07-15-2014$ & 4.00 & 4.00 & 3.75 & 40 & 60 & - & 1 & 20 \\
\hline 08-14-2014 & 3.75 & 3.50 & 3.50 & 60 & 40 & - & - & \\
\hline 09-11-2014 & 3.50 & 3.25 & 3.25 & 52 & 48 & - & - & \\
\hline $10-16-2014$ & 3.25 & 3.25 & 3.00 & 36 & 64 & - & 1 & -32 \\
\hline $11-18-2014$ & 3.00 & 3.00 & 3.00 & - & 96 & 4 & - & \\
\hline $12-11-2014$ & 3.00 & 3.00 & 3.00 & 8 & 92 & - & - & \\
\hline $01-15-2015$ & 3.00 & 3.00 & 3.00 & 4 & 96 & - & - & \\
\hline $02-12-2015$ & 3.00 & 3.00 & 3.00 & - & 100 & - & - & \\
\hline $03-19-2015$ & 3.00 & 3.00 & 3.00 & - & 96 & 4 & - & \\
\hline $04-16-2015$ & 3.00 & 3.00 & 3.00 & - & 96 & 4 & - & \\
\hline $05-14-2015$ & 3.00 & 3.00 & 3.00 & - & 96 & 4 & - & \\
\hline $06-11-2015$ & 3.00 & 3.00 & 3.00 & - & 96 & 4 & - & \\
\hline
\end{tabular}


Table 13 (continuation)

\begin{tabular}{|c|c|c|c|c|c|c|c|c|}
\hline & \multicolumn{3}{|c|}{ Monetary policy decisions } & \multicolumn{3}{|c|}{ Probabilities } & \multicolumn{2}{|c|}{ Surprise measures } \\
\hline & $\begin{array}{l}\text { MPR (bef. } \\
\text { MPM) }\end{array}$ & $\begin{array}{c}\text { Implied } \\
\text { MPR (av.) }\end{array}$ & $\begin{array}{c}\text { Actual } \\
\text { decision }\end{array}$ & Cut & Maintain & Hike & Surprise & $\begin{array}{l}\text { Change in } \\
\text { probs }(\%)\end{array}$ \\
\hline $07-14-2015$ & 3.00 & 3.00 & 3.00 & - & 100 & - & - & \\
\hline $08-13-2015$ & 3.00 & 3.00 & 3.00 & - & 96 & 4 & - & \\
\hline $09-15-2015$ & 3.00 & 3.00 & 3.00 & - & 72 & 28 & - & \\
\hline $10-15-2015$ & 3.00 & 3.00 & 3.25 & - & 64 & 36 & 1 & 0 \\
\hline $11-12-2015$ & 3.25 & 3.25 & 3.25 & - & 64 & 36 & - & \\
\hline $12-17-2015$ & 3.25 & 3.25 & 3.50 & - & 72 & 28 & 1 & -16 \\
\hline 01-14-2016 & 3.50 & 3.50 & 3.50 & - & 88 & 12 & - & \\
\hline $02-11-2016$ & 3.50 & 3.50 & 3.50 & - & 80 & 20 & - & \\
\hline $03-17-2016$ & 3.50 & 3.50 & 3.50 & - & 84 & 16 & - & \\
\hline $04-12-2016$ & 3.50 & 3.50 & 3.50 & - & 92 & 8 & - & \\
\hline $05-17-2016$ & 3.50 & 3.50 & 3.50 & - & 92 & 8 & - & \\
\hline $06-16-2016$ & 3.50 & 3.50 & 3.50 & - & 96 & 4 & - & \\
\hline $07-14-2016$ & 3.50 & 3.50 & 3.50 & - & 96 & 4 & - & \\
\hline 08-11-2016 & 3.50 & 3.50 & 3.50 & - & 100 & 0 & - & \\
\hline $09-15-2016$ & 3.50 & 3.50 & 3.50 & - & 100 & 0 & - & \\
\hline $10-18-2016$ & 3.50 & 3.50 & 3.50 & 4 & 96 & - & - & \\
\hline $11-17-2016$ & 3.50 & 3.50 & 3.50 & 8 & 92 & - & - & \\
\hline $12-13-2016$ & 3.50 & 3.50 & 3.50 & 24 & 76 & - & - & \\
\hline $01-19-2017$ & 3.50 & 3.50 & 3.25 & 44 & 56 & _- & 1 & -20 \\
\hline $02-14-2017$ & 3.25 & 3.25 & 3.25 & 24 & 76 & - & - & \\
\hline $03-16-2017$ & 3.25 & 3.25 & 3.00 & 28 & 72 & - & 1 & 12 \\
\hline 04-13-2017 & 3.00 & 3.00 & 2.75 & 40 & 60 & - & 1 & -16 \\
\hline $05-18-2017$ & 2.75 & 2.75 & 2.50 & 24 & 76 & - & 1 & -20 \\
\hline $06-15-2017$ & 2.50 & 2.50 & 2.50 & 4 & 96 & - & - & \\
\hline $07-13-2017$ & 2.50 & 2.50 & 2.50 & 12 & 88 & - & - & \\
\hline $08-17-2017$ & 2.50 & 2.50 & 2.50 & 8 & 92 & - & - & \\
\hline
\end{tabular}

In fact, the average (absolute value) jump in probabilities of a hike or a cut when the market is surprised is $17 \%$, compared to the $7 \%$ when it is not surprised. This shows that the market reacts to new information after a policy meeting. In particular it is observed that the month to month (meeting to meeting) standard deviation of monetary policy changes is $9 \mathrm{bps}$ for the month after a surprise compared to $4 \mathrm{bps}$ when it is not.

It is interesting that surprises "cluster" in the first months before a switch in policy cycles, after which implied rates adapt to better interpret CB future decisions. The main conclusions to be drawn here is that the market is usually right when it prices that rates will stay unchanged, and they do most of the time. However, when policy cycles change, they do so suddenly and surprise the market, that reacts to said information and improves its pricing.

In short, the market is often surprised when rates are changed. In 20 meetings that concluded in hikes or cuts, the market was surprised 15 times $^{20}$. As seen before, the market was surprised more often when cuts took place, and only twice did it properly priced cuts. When it was not surprised, the market only expected the change with a $56 \%$ probability. When it was surprised, the market expected the change with

20 In three occasions, the market was not surprised in the direction but in the magnitude. This means that the total number of surprises was 18 
a $72 \%$ probability. This means, that if the Central Bank monitors average implied rates extracted from swap rates, it has no problem with surprising the market, or fails to actively communicate intended changes.

Since one month ahead policy decisions are extracted from interpolated rates, it may very well be that the slope of the curve is not steep enough to anticipate changes. Instead, the board of the Central Bank may focus on surveys rather than implied prices and agents may not actively trade three month swaps as much as longer maturities. In fact, absolute pricing errors negatively correlate with periods of steeper curves and are smaller when it comes to anticipating hikes, but the same is not true regarding cuts, and negative slopes are less frequent. In any case, the general lack of predictive power for the curve and its bias to price hikes correlates with its medium-term interest rate term structure.

\section{CONCLUSION}

It is concluded that the paths of monetary policy rates that are implied in swap rates are usually different (higher by 25bps) than actual monetary policy rates. This means that, on average, medium term swap rates (up to 15 months) contain a term premium that is quantifiable and depends on the cycle of monetary policy. In fact, hike cycles, defined as the period in which the slope of the curve is steep enough to justify increases in upcoming monetary policy rates show an average of 2.1 hikes of 25bps in 15 months. Accordingly, cut cycles show 1.5 cuts, whereas the whole series shows 0.9 hikes, regardless of the fact that cuts happened twice as often as hikes.

The difference in the number of implied movements for different cycles is significant. In fact, it is shown that there exists a positive correlation between current policy cycles and the path of implied future rates, and that average accumulated month to month premiums are higher for more hawkish scenarios and vice versa. It is also concluded that in a world where monetary policy generally reverts to the mean, swap curves strictly price hikes for the medium term whereas cuts are only priced for the first six months of the implied path. Moreover, on average, the market mispriced 15 month ahead rates. In particular periods, pricing errors are significant and fail to recollect past information on monetary policy rates.

This article also looked at the probability of changes for the short end of the implied path of policy rates. By extracting one month ahead probabilities of policy decisions it is shown that even if hikes happen much less often than cuts, they are priced much more often. This difference is so dramatic, that in all of our sample, the market was generally surprised before cuts happened, and was uncertain when hikes happened. This may be explained by the slope of the curve rather than by arbitrage measures for three month swaps. In any case, we have shown that swap rates are an ineffective tool to extract future monetary policy rates, and that they are particularly ineffective to price expansionary cycles of monetary policy. 
More research is needed to identify the nature behind the term premiums existing in the curve of implied monetary policy rates and on the nature of the term premium component of the slope of the swap curve in general. Finally, further work on the subject of implied monetary policy will determine if the change in monetary policy meetings regime had any effect on improving the pricing of future policy paths, or even reducing the variability of said paths.

\section{REFERENCES}

EMMONS, W. R. and YEAGER, T. J. (2002). The futures market as forecasting tool: An imperfect crystal ball. The Regional Economist, pages 10-11.

FONTAINE, J.-S. (2016). What do fed funds futures tell us about monetary policy uncertainty. Available at SSRN 1343913.

VARELA, F. (2007). Mercados de derivados: swap de tasas promedio camara y seguro inflación. Studies in Economic Statistics, Central Bank of Chile, 56.

KEASLER, T. R. and GOFF, D. C. (2007). Using fed funds futures to predict a federal reserve rate hike. Journal of Economics and Finance Education, 6(2): 9-14.

NOSAL, E. (2001). How well does the federal funds futures rate predict the future federal funds rate? Federal Reserve Bank of Cleveland, Economic Commentary (October), pages 1-4.

SOTZ, C.; ALARCÓN, F. (2007). Mercado swap de tasas de interés y expectativas de tpm e inflación. Notas de Investigación Journal Economía Chilena (The Chilean Economy), 10 (2): 97-102. 
